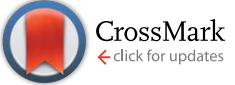

Cite this: RSC Adv., 2015, 5, 41894

Received 17th March 2015

Accepted 1st May 2015

DOI: $10.1039 / c 5 r a 04691 b$

www.rsc.org/advances

\title{
Synthesis of high-quality carbon nanotube fibers by controlling the effects of sulfur on the catalyst agglomeration during the direct spinning process $\uparrow$
}

\begin{abstract}
Sung-Hyun Lee, ${ }^{a}$ Junbeom Park, ${ }^{a}$ Hye-Rim Kim, ${ }^{a}{ }$ Jaegeun Lee ${ }^{b}$ and Kun-Hong Lee*a
The effects of sulfur on the size of iron catalyst particles and synthesized carbon nanotubes (CNTs) were investigated during the direct spinning of CNT fibers. CNT fibers containing mainly double-walled CNTs (DWCNTs) 5-10 nm in diameter were synthesized from acetone, ferrocene, and thiophene, whereas CNT fibers containing mainly single-walled CNTs (SWCNTs) 1-1.5 nm in diameter were obtained from methane, ferrocene, and sulfur. The differences in the products arose from the anti-agglomeration effects of the sulfur atoms, which were adsorbed onto the surfaces of the iron catalyst particles, as indicated by direct experimental evidence. A model for the interplay between sulfur atoms and the iron catalyst particles was proposed based on these results, and experimental confirmation of this model was sought by modulating the sulfur injection time into the reactor at different temperatures. This simple experimental modification was used to control the majority of CNTs in the CNT fibers synthesized from SWCNTs, through DWCNTs, and finally to multi-walled CNTs (MWCNTs), with corresponding $I_{\mathrm{G}} / /_{\mathrm{D}}$ ratios that varied from 26.9 to 1.5 .
\end{abstract}

\section{Introduction}

Carbon nanotubes (CNTs) have excellent properties, such as a high tensile strength, high thermal conductivity, and high electrical conductivity. ${ }^{1,2}$ Although a variety of applications have been proposed, including composite materials, coatings and films, microelectronics, electrochemical energy storage applications, and field emission applications, ${ }^{3-7}$ the industrial use of mass quantities of CNTs has not been realized to date. One candidate material with promise for some of these applications is the CNT fiber, which is a collection of many CNTs aligned along the fiber axis. CNT fibers can be fabricated using a variety of methods. ${ }^{8-11}$ Research in this field has been greatly accelerated after reports of strong CNT fibers $(8.8 \mathrm{GPa})$ in $2007 . .^{12}$ Applications of CNT fibers include composite materials, ${ }^{13}$ artificial muscles, ${ }^{14,15}$ supercapacitors, ${ }^{16-18}$ torsional actuators, ${ }^{19-22}$ strain/damage sensors, ${ }^{23}$ and biosensors. ${ }^{24}$

Methods for fabricating CNT fibers may be classified into three categories: forest spinning, solution spinning, and direct spinning. ${ }^{25}$ Each method has its own merits and drawbacks.

${ }^{a}$ Department of Chemical Engineering, Pohang University of Science and Technology (POSTECH), San 31, Hyoja-Dong, Nam-Gu, Pohang, Gyungbuk, 790-784, South Korea.E-mail: ce20047@postech.ac.kr

${ }^{b}$ Carbon Convergence Materials Research Center, Korea Institute of Science and Technology, 92, Chudong-ro, Bongdong-eup, Wanju-gun, Jeollabuk-do 565-905, South Korea

$\dagger$ Electronic supplementary information (ESI) available. See DOI: 10.1039/c5ra04691b
Direct spinning synthesizes a CNT aerogel in the vapor phase, and continuous CNT fibers or ribbons are drawn from the CNT aerogel. ${ }^{10}$ Direct spinning is a one-step process during which CNT synthesis and fiber formation occur simultaneously in a single reactor to enable the continuous production of CNT fibers. ${ }^{26}$ The growth rate of CNTs is high $\left(0.1-1 \mathrm{~mm} \mathrm{~s}^{-1}\right),{ }^{27}$ and the average lengths of the synthesized CNTs may be as long as the millimeter scale. The best tensile strength ( $8.8 \mathrm{GPa})$ achieved among CNT fibers was reported with fibers prepared using this method, by optimizing the synthesis conditions. ${ }^{12}$

The quality of a CNT fiber depends strongly on the quality of the constituent CNTs. The yield and quality of CNTs tend to increase with decreasing diameter and/or increasing growth rate of the CNTs. ${ }^{28-31}$ The CNT diameter is closely related to the catalyst size. Small catalyst sizes produce small-diameter CNTs. ${ }^{32}$

Sulfur is an important element in the synthesis of CNTs. ${ }^{10}$ Sulfur activates metal catalyst particles and increases the yields of CNTs through fast nucleation. ${ }^{27}$ The surface free energy of $\mathrm{FeS}\left(-84.17 \mathrm{~kJ} \mathrm{~mol}^{-1}\right)$ at the eutectic temperature is much lower than that of $\alpha-\mathrm{Fe}\left(-0.19 \mathrm{~kJ} \mathrm{~mol}^{-1}\right)$. Nucleation of CNTs is more favorable at the catalyst particles having a low surface free energy, thereby increasing the CNT yield. ${ }^{33}$ The addition of sulfur protects small catalytic particles from poisoning effects and increases the amount of well-aligned single-walled CNTs (SWCNTs) produced. ${ }^{34}$ Sulfur also affects the diameters and wall numbers of CNTs. The diameter of a CNT depends on the molar ratio of sulfur to carbon. ${ }^{35}$ The number of graphitic layers present in a CNT is controlled by sulfur, ${ }^{33}$ and the SWCNTs, 
double-walled CNTs (DWCNTs), and multi-walled CNTs (MWCNTs) could be selectively synthesized by changing the amount of sulfur present. ${ }^{36}$

In this paper, we investigated the effects of sulfur on the sizes of the iron catalyst particles and, thus, the quality of the synthesized CNTs produced by direct spinning. Previous reports proposed that sulfur formed a coating on iron catalyst particles and prevented the further growth of catalyst particles. This proposal, however, was only indirectly supported by the synthesis of SWCNTs. ${ }^{37}$ Here, we provide direct experimental evidence that sulfur present in the iron catalyst particles controls the diameter of the catalyst particles and, thus, the diameters of the CNTs. Experimental results revealed that the different promoters containing sulfur atoms used in the CNT synthesis affected the morphology and the $I_{\mathrm{G}} / I_{\mathrm{D}}$ ratio in the resulting CNTs. A detail model of the catalyst formation and CNT growth was proposed based on the experimental observations. Finally, a simple experimental technique for controlling the type of CNT synthesized was devised.

\section{Experimental}

Experiments were performed in three ways. CNT fibers were synthesized using liquid feeds or gas feeds to demonstrate the effects of sulfur on the catalyst size and, therefore, the diameter of the CNTs. Finally, The CNT fibers were again synthesized in the presence of sulfur, but the time permitted for contact between the catalyst particles and sulfur atoms was controlled by the position of the sulfur injection tube. The last set of experiments was designed to test our model of the effects of sulfur on the catalyst particle size. Typical experimental conditions are given in Table 1.

Double-walled CNTs (DWCNTs) were synthesized using a liquid solution feedstock. Acetone was used as the carbon precursor, ferrocene was used as the catalyst precursor, and thiophene was used as the sulfur precursor. A mixed solution (acetone, ferrocene, thiophene) was injected from the top of the vertical reactor using a syringe pump operated at a constant rate. As the precursors thermally decomposed, carbon, iron, and sulfur atoms were generated in the reactor. The concentration of the catalyst was adjusted by controlling the amounts of ferrocene and thiophene present in the acetone.
By contrast, SWCNTs were synthesized using gaseous feeds. The catalyst precursor, ferrocene, was not changed, but the sulfur promoter was changed from thiophene to sulfur to control the catalyst size. Methane was used as a carbon source instead of acetone. Methane, ferrocene, and sulfur were introduced into a vertical reactor through separate tubes. The gaseous feed set-up is illustrated schematically in Fig. 4 . The amounts of sulfur and ferrocene were individually controlled by varying the pre-heating temperature.

The catalyst precursors were evaporated in the pre-heat furnace and were introduced into the vertical reactor using a carrier gas. The amount of catalyst present was controlled by adjusting the pre-heat temperature according to the following equation. The vapor pressure of ferrocene was calculated using the following equation. ${ }^{38}$

$$
\ln \left(\frac{P_{\mathrm{e}}}{\mathrm{Pa}}\right)=\frac{273.6}{R}-\frac{81535.7}{R(T / \mathrm{K})}-\frac{29.6}{R} \ln \left(\frac{T / \mathrm{K}}{298.15}\right)
$$

here, $P_{\mathrm{e}}$ is the vapor pressure of ferrocene $(\mathrm{Pa}), T$ is the absolute temperature $(\mathrm{K})$, and $R$ is the universal gas constant $(8.3145 \mathrm{~J}$ $\mathrm{mol}^{-1} \mathrm{~K}^{-1}$ ). The vapor pressure of sulfur was calculated using the modified Antoine equation. ${ }^{39}$

$$
\log (P)=16.83213-0.0062238(273.15+T)-\frac{5405.1}{(273.15+T)}
$$

here, $P$ is the vapor pressure of sulfur $(\mathrm{mm} \mathrm{Hg}), T$ is the temperature $\left({ }^{\circ} \mathrm{C}\right)$. This equation is valid over the temperature range $120-325{ }^{\circ} \mathrm{C}$.

The sublimation rate of ferrocene and the evaporation rate of sulfur were calculated using the equation ${ }^{38}$

$$
\tau=\alpha\left(P_{\mathrm{e}}-P_{\mathrm{h}}\right) \sqrt{\frac{M}{2 \pi R T}}
$$

where $\tau$ is the sublimation and evaporation rate $\left(\mathrm{g} \mathrm{s}^{-1}\right), \alpha$ is a constant $(0.0001), P_{\mathrm{e}}$ is the vapor pressure of ferrocene $(\mathrm{Pa}), P_{\mathrm{h}}$ is the pressure of ferrocene in the gas phase ( $\mathrm{Pa})$, and $M$ is the molecular weight $\left(\mathrm{g} \mathrm{mol}^{-1}\right)$.

The synthesized CNTs were present as bundles due to van der Waals forces in the reaction zone, and these bundles agglomerated together to form a CNT aerogel. The CNT aerogel moved downward from the reaction zone to the bottom of the vertical reactor in the carrier gas. The CNT aerogel was pulled out from the vertical reactor in the form of a film. This CNT film

\begin{tabular}{|c|c|c|c|c|c|c|c|c|}
\hline & $\begin{array}{l}\text { Carbon } \\
\left(\mathrm{mol} \mathrm{min}^{-1}\right)\end{array}$ & $\begin{array}{l}\text { Catalyst } \\
\left(\mathrm{mol} \mathrm{min}^{-1}\right)\end{array}$ & $\begin{array}{l}\text { Promoter } \\
\left(\mathrm{mol} \mathrm{min}^{-1}\right)\end{array}$ & $\begin{array}{l}\text { Carrier gas } \\
\left(\mathrm{mol} \mathrm{min}^{-1}\right)\end{array}$ & & $\begin{array}{l}\text { Oxygen } \\
\left(\mathrm{mol} \mathrm{min}^{-1}\right)\end{array}$ & $\begin{array}{l}\text { Reaction } \\
\text { temperature }\left({ }^{\circ} \mathrm{C}\right)\end{array}$ & $\begin{array}{l}\text { CNT type } \\
\text { production } \\
\text { rate }\left(\mathrm{m} \mathrm{min}^{-1}\right)\end{array}$ \\
\hline \multirow[t]{2}{*}{ Liquid feeds } & Acetone & Ferrocene & Thiophene & Hydrogen & Argon & - & - & DWCNTs \\
\hline & $2.3 \times 10^{-3}$ & $1.2 \times 10^{-5}$ & $4.8 \times 10^{-6}$ & $4.1 \times 10^{-2}$ & - & - & 1170 & TWCNTs 7.44 \\
\hline \multirow[t]{2}{*}{ Gas feeds } & Methane & Ferrocene & Sulfur & Hydrogen & Argon & Water & - & SWCNTs 1.87 \\
\hline & $3.3 \times 10^{-3}$ & $5.4 \times 10^{-4}$ & $3.5 \times 10^{-4}$ & $1.8 \times 10^{-2}$ & $1.4 \times 10^{-2}$ & $6.4 \times 10^{-5}$ & 1135 & \\
\hline \multirow{2}{*}{$\begin{array}{l}\text { Gas feeds (position of } \\
\text { the sulfur injection }\end{array}$} & Methane & Ferrocene & Sulfur & Hydrogen & Argon & - & & SWCNTs 5.66 \\
\hline & $2.0 \times 10^{-3}$ & $2.1 \times 10^{-4}$ & $4.5 \times 10^{-4}$ & $1.6 \times 10^{-2}$ & $1.6 \times 10^{-2}$ & - & 1175 & \\
\hline
\end{tabular}
was passed through the water bath immediately below the

Table 1 Typical direct spinning synthesis conditions of the DWCNT fibers and SWCNT fibers tube was varied) 
reactor, and the shape of the CNT film was changed to a fiber due to compaction in a poor solvent, water.

A morphological analysis of the CNT fibers and an elemental analysis of the catalyst particles were conducted using fieldemission scanning electron microscopy (FESEM, JEOL JMS$7400 \mathrm{~F}$, operated at $10 \mathrm{keV}$ ), high-resolution scanning transmission electron microscopy (Cs-corrected HR-STEM, JEOL JEM-2100F with electron energy loss spectroscopy (EELS)) and energy dispersive spectrometer (EDS), operated at $200 \mathrm{kV}$. The $I_{\mathrm{G}} / I_{\mathrm{D}}$ ratios of the synthesized CNT fibers were measured by Raman spectroscopy (Horiba Jobin Yvon, LabRam HR, He-Ne laser $633 \mathrm{~nm}$ ).

\section{Results and discussions}

Fig. 1a-c show the CNT fiber synthesized using acetone, ferrocene, and thiophene. The CNTs that constituted the CNT fibers were arranged in an axial structure (Fig. 1b). The CNTs were mainly DWCNTs, and the diameters of the DWCNTs fell in the range 5-10 nm (Fig. 1c). A similar observation has been reported previously. ${ }^{27}$ It should be noted that the diameters of the DWCNTs synthesized by direct spinning exceeded the diameters of the DWCNTs synthesized by other methods. ${ }^{33}$ On the other hand, Fig. 1d-f show the CNT fibers synthesized using methane, ferrocene, and sulfur. Again, the CNTs were arranged along the axial direction of the fiber (Fig. 1d), but empty spaces were observed on the surfaces of the CNT fibers, indicating that the packing density was low (Fig. 1e). The CNTs were mainly composed of SWCNTs 1.5-2.0 nm in diameter (Fig. 1f).

The above results agreed well with previous reports ${ }^{37}$ that sulfur coatings on small catalyst particles inhibited the further growth of the catalyst particles. This claim was experimentally confirmed by imaging the catalyst particles using TEM, EELS, and EDX, as shown in Fig. 2. The use of thiophene as the sulfur promoter yielded catalyst particle diameters in the range 4-20
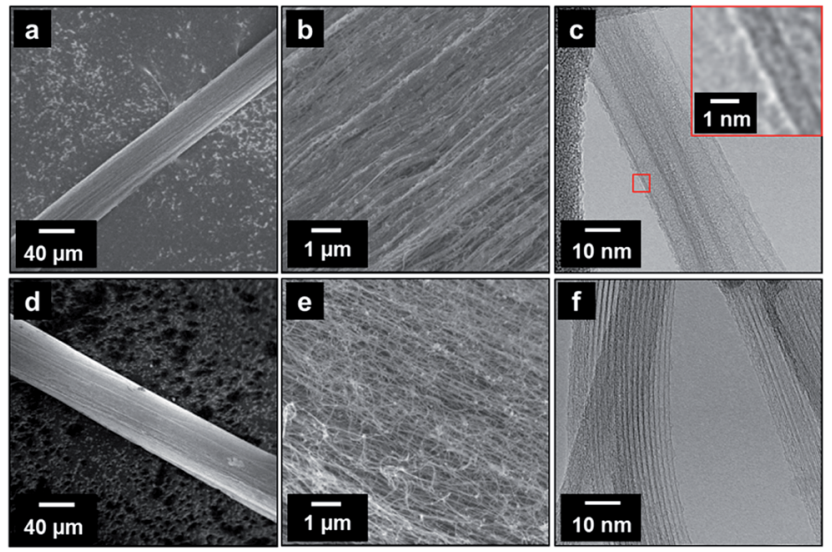

Fig. 1 Effects of the different feed materials introduced during the fabrication of CNT fibers by direct spinning. (a)-(c) CNT fibers synthesized from acetone, ferrocene, and thiophene. The CNTs mainly featured double walls and large diameters $(5-10 \mathrm{~nm})$. (d)-(f) The CNT fibers synthesized from methane, ferrocene, and sulfur. The bundle comprised SWCNTs, which were 1.5-2.0 nm in diameter. $\mathrm{nm}$, and the highest frequency was $8 \mathrm{~nm}$ (Fig. 2a). The diameters of the CNTs were similar to the sizes of the catalyst particles. Ferrocene decomposes around $400{ }^{\circ} \mathrm{C}$; therefore, iron atoms were generated at the top of the reactor (see Fig. 4). The iron atoms stuck together to form iron catalyst particles, and the catalyst particles grew with the inclusion of more iron atoms. Thiophene begins to decompose when it reaches a much higher temperature $\left(800^{\circ} \mathrm{C}\right)$. The significant difference between the decomposition temperatures of ferrocene and thiophene meant that the catalyst particles tended to grow larger prior to the start of the sulfur hindrance of catalyst aggregation. The decomposition of thiophene generated sulfur atoms that surrounded the surfaces of the iron catalyst particles. The EELS
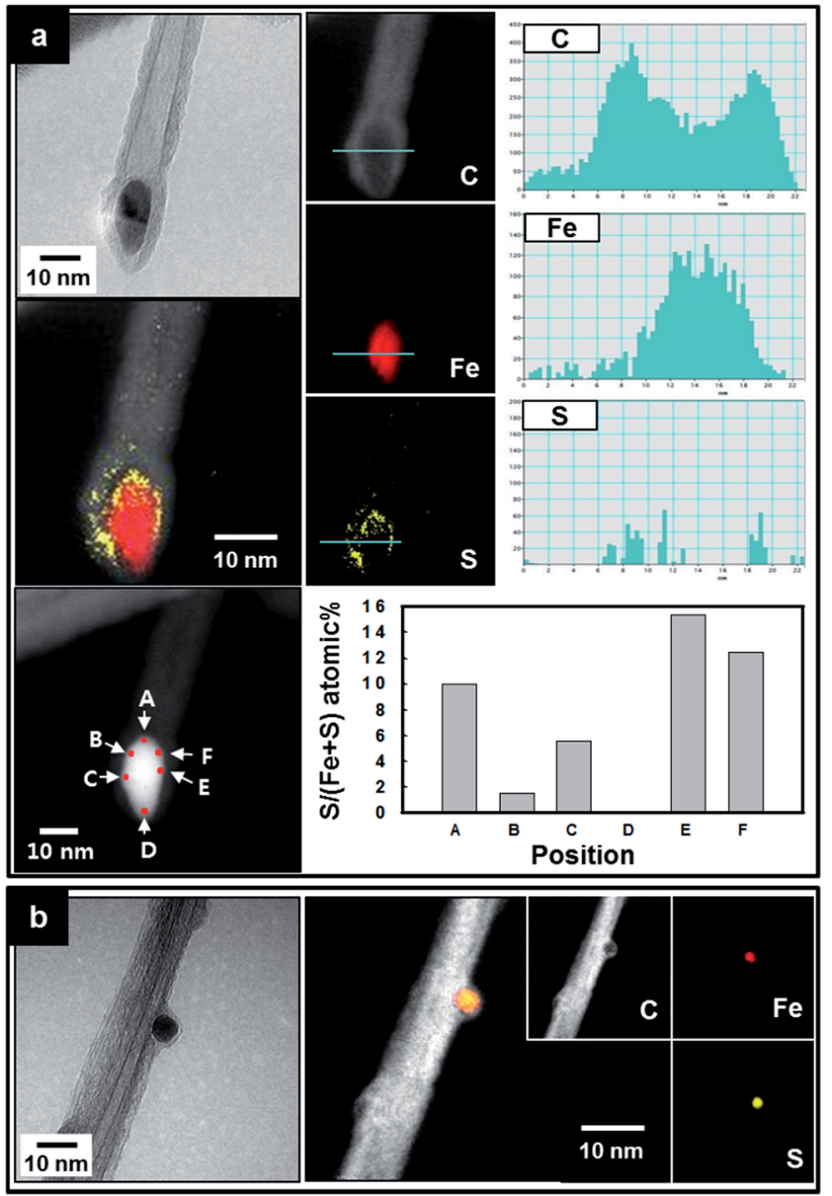

Fig. 2 The distribution of sulfur atoms throughout the catalyst particles. Gray, red, and yellow colors in the EELS mapping represent carbon, iron, and sulfur atoms. (a) The CNTs were synthesized from acetone, ferrocene, or thiophene. The iron catalyst particle was formed by the decomposition of ferrocene prior to the decomposition of thiophene, which supplied sulfur to the catalyst. The element profiles revealed that the sulfur atoms were mainly present on the surfaces of the relatively large iron catalyst particles. The EDS analysis showed that the CNTs grew from spots on the catalyst particle at which sulfur atoms were concentrated. (b) The CNTs were synthesized from methane, ferrocene, and sulfur. In this case, sulfur was already present prior to the decomposition of ferrocene, so that sulfur atoms were distributed evenly throughout the small iron catalyst particles. The growth of catalyst particles was inhibited by the presence of sulfur. 


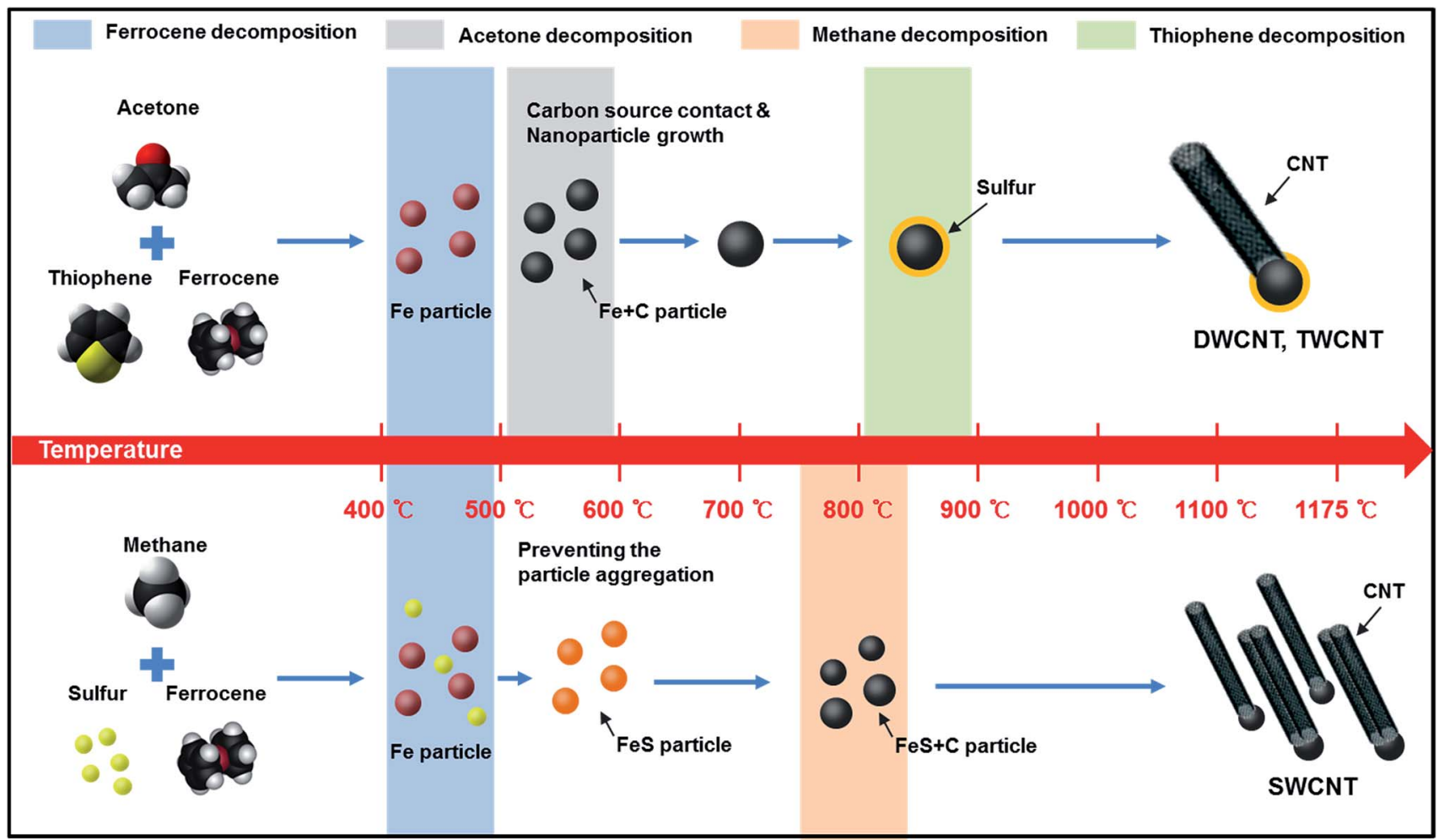

Fig. 3 The type of CNT synthesized depended on the catalyst size. Thermal decomposition of ferrocene occurred at $400{ }^{\circ} \mathrm{C}$, and iron catalyst particles formed. For the case in which thiophene was used as a promoter, iron catalyst particles formed and grew, followed by the binding of sulfur atoms to the surfaces of the large iron particles. DWCNTs and TWCNTs with large diameters were synthesized. For the case in which sulfur was used as a promoter, the sulfur atoms were present prior to the decomposition of ferrocene. Small catalyst particles formed with an even distribution of sulfur atoms throughout the catalyst particles. SWCNTs were the main product.

mapping shown in Fig. 2a indicated that sulfur atoms were mainly present on the surfaces of the large iron catalyst particle. The sulfur activated the surface of the iron catalyst, so that carbon atoms readily formed graphitic layers on the catalyst surface. The EDS analysis revealed that the CNTs grew from the spots of the catalyst particle where the sulfur atoms were concentrated. The carbon atoms diffused along the surface of the catalyst particles and deposited in the form of a graphitic layer at the lower surface free energy point of the catalyst. ${ }^{27,33} \mathrm{In}$ this way, CNTs with large diameters and multiple graphitic layers were synthesized from the large catalyst particles.

On the other hand, the sizes of the catalyst particles decreased when sulfur itself was used as the promoter (Fig. 2b). In this case, sulfur atoms were already present prior to the generation of iron atoms from the ferrocene decomposition process. Because the sulfur atoms prevented the aggregation of iron catalyst particles, the catalyst particles were smaller. The EELS mapping shown in Fig. $2 \mathrm{~b}$ revealed that sulfur was evenly distributed throughout the catalyst particles in this case. The diameters of the CNTs also decreased accordingly (see Fig. 5a).

A cartoon illustration of the role of sulfur in determining the sizes of the catalyst particles and the diameters of the synthesized CNTs is presented in Fig. 3. The most important factor is the decomposition temperatures of the precursors. The use of acetone, thiophene, and ferrocene as feed materials resulted in the decomposition of ferrocene at $400{ }^{\circ} \mathrm{C}$, whereas thiophene began to decompose at $800{ }^{\circ} \mathrm{C}$. Once ferrocene had decomposed, the iron catalyst particles formed and grew through the addition of iron atoms or through the aggregation of iron particles, until the temperature reached $800{ }^{\circ} \mathrm{C}$. After this temperature, the sulfur atoms accumulated on the surfaces of the iron catalyst particles, and the sulfur atoms inhibited the catalyst growth. The large difference between the decomposition temperatures of ferrocene and thiophene resulted in the formation of large catalyst particles, and DWCNTs (and some triple-walled CNTs (TWCNTs)) with large diameters were synthesized (Fig. S1 $\dagger$ ). On the other hand, the use of methane, sulfur, and ferrocene as feed materials produced sulfur atoms prior to the decomposition of ferrocene. Therefore, sulfur atoms were present deep inside the iron catalyst particles, from the nucleation stage of the iron catalysts, and these atoms hindered the further growth of iron catalyst particles. As a result, iron catalyst particles were small and had sulfur atoms distributed evenly throughout. SWCNTs with small diameters were the main products in this case.

This model for the effects of sulfur on the catalyst size and synthesized CNTs was tested by introducing a simple modification into the experimental setup. The length of the sulfur injection tube was varied, as shown in Fig. 4. Sulfur contacted the iron catalyst particles at different temperatures with this modification. The temperature of the top part of the vertical reactor increased rapidly with the flow direction, reaching 


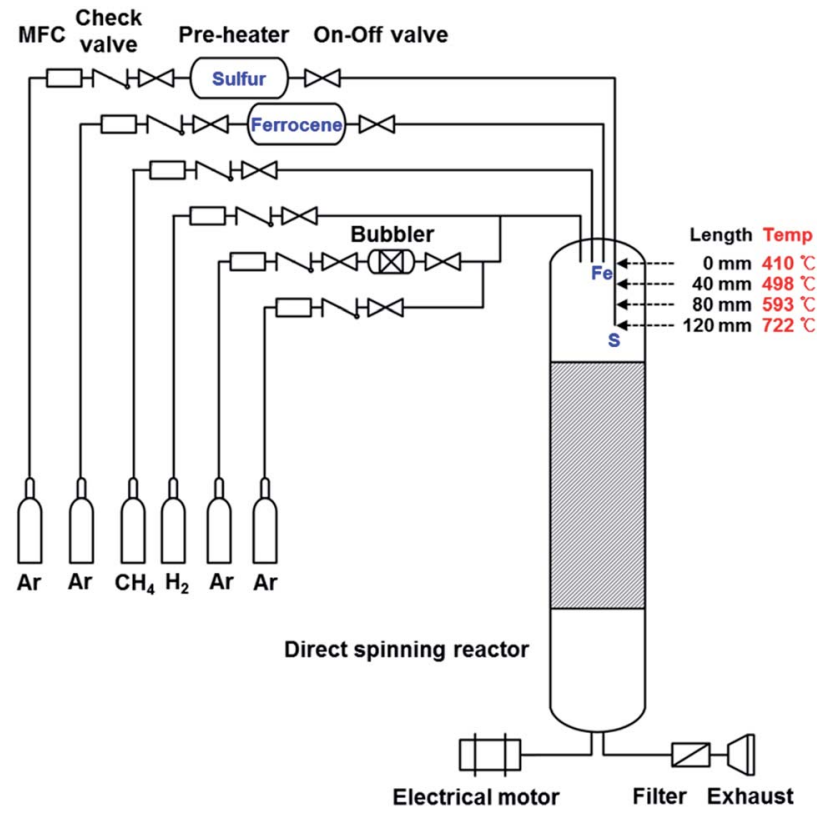

Fig. 4 Schematic diagram showing the vertical tube reactor. Sulfur was demonstrated to control the catalyst size by varying the position of the sulfur injection tube. Each feed material was separately injected from the top of the reactor. As the length of the sulfur injection tube increased, the contact time between the catalyst particles and the sulfur atoms decreased.

$410{ }^{\circ} \mathrm{C}$ for the $0 \mathrm{~mm}$ tube length positioned at the top of the reactor, $498{ }^{\circ} \mathrm{C}$ for the $40 \mathrm{~mm}$ tube, $593{ }^{\circ} \mathrm{C}$ for the $80 \mathrm{~mm}$ tube, and $722{ }^{\circ} \mathrm{C}$ for the $120 \mathrm{~mm}$ tube. As the length of the sulfur

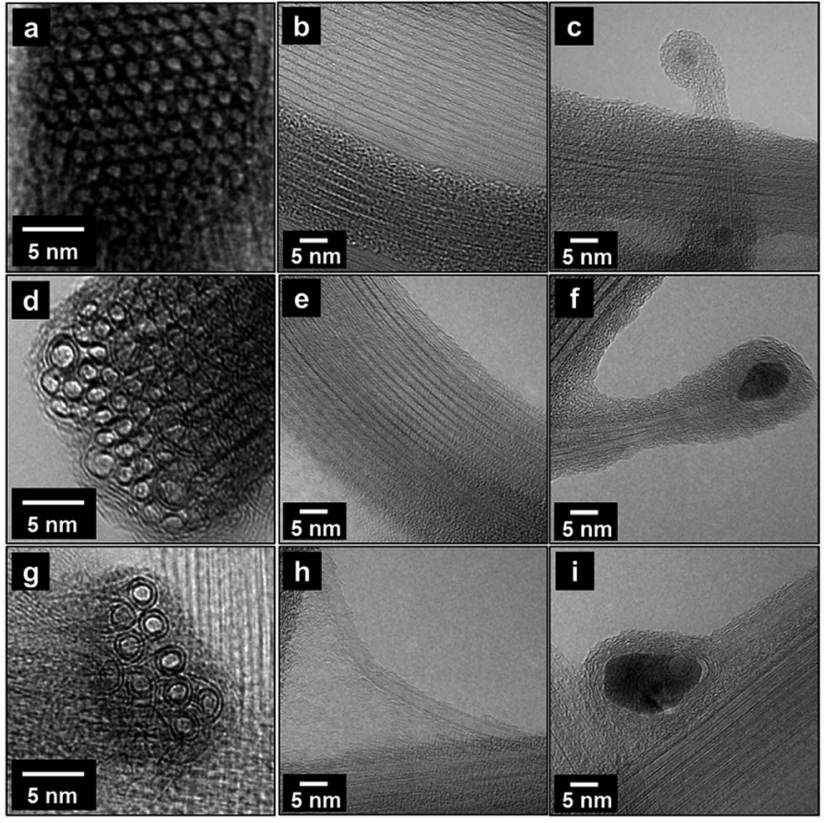

Fig. 5 Change in the CNTs synthesized as a function of the sulfur injection point. The positions of the end of sulfur injection tube were $(a-c) 0 \mathrm{~mm},(\mathrm{~d}-\mathrm{f}), 40 \mathrm{~mm}$, and $(\mathrm{g}-\mathrm{i}) 80 \mathrm{~mm}$ from the top of the vertical tube reactor. A delay in the time of sulfur injection increased the size of the iron catalysts. The CNTs synthesized changed from SWCNTs to DWCNTs. injection tube increased, contact between the iron catalyst particles and the sulfur atoms was delayed. The decomposition temperature of methane exceeded $750^{\circ} \mathrm{C}$ in the presence of the iron catalyst, ${ }^{40}$ therefore, the effects of sulfur on the formation of the iron catalysts could be investigated unambiguously without the influence of the carbon atoms.

The experimental results are presented in Fig. 5-7. As expected, the sizes of the catalyst particles increased with the length of the sulfur injection tube, and the majority of synthesized CNTs changed from SWCNTs (0 mm, Fig. 5a) to DWCNTs ( $80 \mathrm{~mm}$, Fig. $5 \mathrm{~g}$ ). A sulfur injection tube length of $40 \mathrm{~mm}$, from the top of the vertical reactor, yielded SWCNTs and DWCNTs simultaneously in a single bundle. A sulfur injection tube length of $120 \mathrm{~mm}$ yielded MWCNTs (not shown here).

We measured the sizes of 50-70 catalyst particles of each sample (in the case of $120 \mathrm{~mm}, 26$ catalyst particles were measured), and the size distributions of catalyst particles are given in Fig. 6. Fig. 6a shows the size distribution curves for catalyst particles, which move to the right (which corresponds to the direction of larger catalyst size) and become wider as the length of the sulfur injection tube increases. A similar trend is observed in the diameter distributions of synthesized CNTs, which is shown in Fig. 6b. The actual size data for catalyst particles and synthesized CNTs are reported as histograms in the ESI (Fig. S3†).
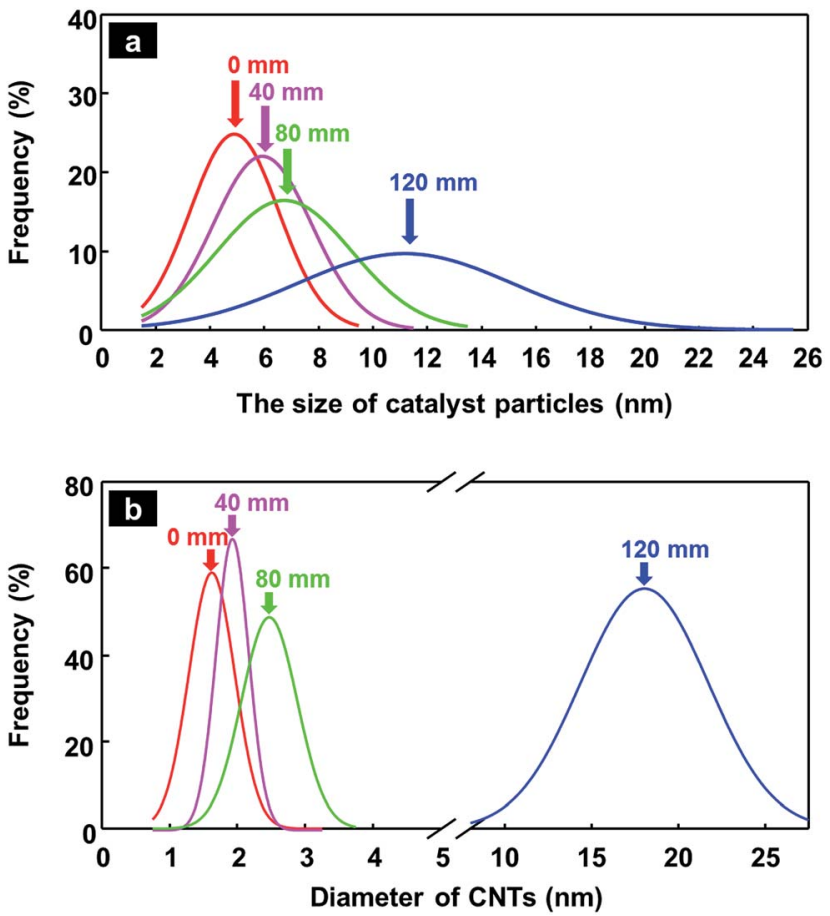

Fig. 6 The size distribution curves of (a) the catalyst particles and (b) the diameters of CNTs. The positions of sulfur injection tubes were 0 , 40,80 , and $120 \mathrm{~mm}$ from the top of the vertical tube reactor. The size distribution curves for the catalyst particles move to the right which corresponds to the direction of larger catalyst size and become wider as the length of the sulfur injection tube increases. A similar trend is observed in the diameter distributions of synthesized CNTs. 
The quality of the synthesized CNTs was investigated using Raman spectroscopy. The G peak $\left(1590 \mathrm{~cm}^{-1}\right)$ is associated with the $\mathrm{sp}^{2}$ bonds of the carbon atoms and is generally used as an indicator of graphitization, whereas the D peak $\left(1350 \mathrm{~cm}^{-1}\right)$ is associated with the $\mathrm{sp}^{3}$ bonds of carbon atoms and used as an indicator of defect structures. The use of sulfur as a promoter resulted in a decrease in the $I_{\mathrm{G}} / I_{\mathrm{D}}$ ratio as the length of the sulfur injection tube increased: from 26.9 at $0 \mathrm{~mm}$ to 1.5 at 120 mm (Fig. 7). Early exposure of the catalyst particles to sulfur indeed enhanced the quality of the synthesized CNTs. The small-diameter CNTs displayed a higher growth rate and improved the yield and quality of the CNTs. ${ }^{28-31}$

The radial breathing mode (RBM) peaks between 100 and $300 \mathrm{~cm}^{-1}$ appeared in the Raman spectra collected from the CNT fibers synthesized with injection tube lengths of 0-80 $\mathrm{mm}$, indicating that thin-walled and small-diameter CNTs were synthesized. The RBM frequencies $(v)$ of SWCNTs and DWCNTs vary as the reciprocal of their diameters (dt) via a linear relationship: $\mathrm{dt}=248 / \nu \mathrm{nm} .{ }^{41}$ The diameters of the CNTs ranged from 1.2 to $1.7 \mathrm{~nm}$, according to this equation, as confirmed by the TEM images (Fig. 5). The $I_{\mathrm{G}} / I_{\mathrm{D}}$ ratio, however, reached 1.5 for a tube length of $120 \mathrm{~mm}$, indicating that the number of thin-walled, small-diameter CNTs decreased significantly. This CNT fiber contained mostly MWCNTs, as evidenced by the disappearance of the RBM peak. TEM studies revealed that the MWCNTs were covered by a thick layer of
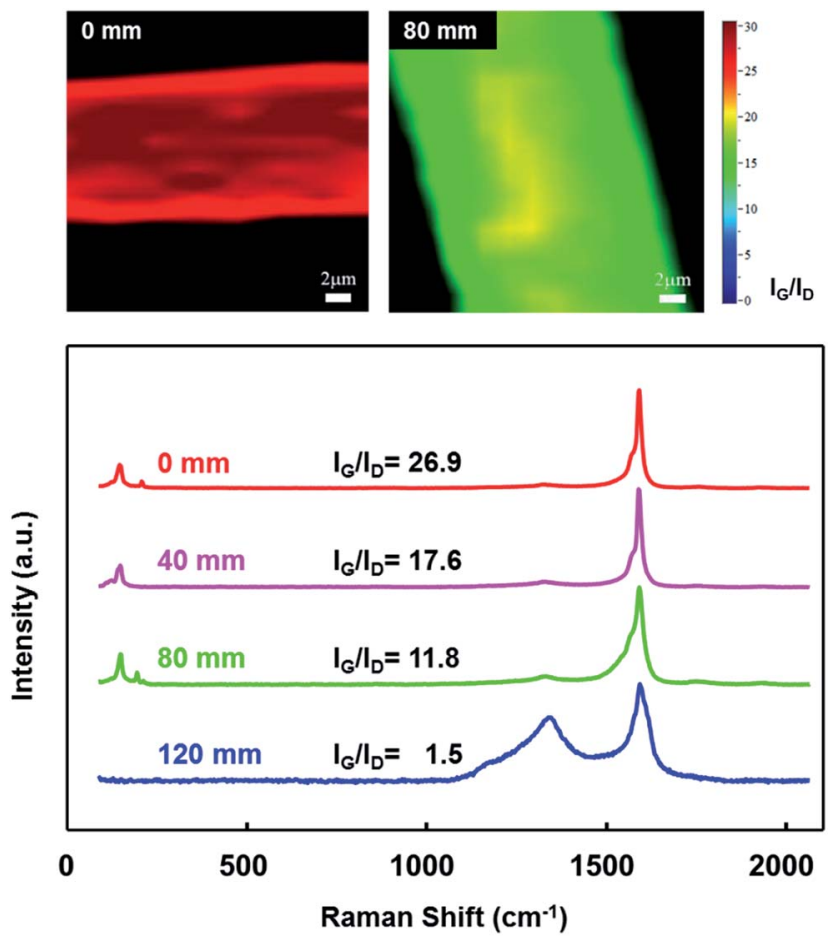

Fig. 7 The $I_{G} / I_{D}$ ratio of the CNT fibers decreased as the length of the sulfur injection tube increased, indicating that large catalyst particles decreased the quality of the synthesized CNTs. Raman mapping images show that the CNT fibers displayed a uniform $I_{\mathrm{G}} / I_{\mathrm{D}}$ ratio over a wide area. (The numbers on the color bar indicate the values of the $I_{\mathrm{G}} /$ $I_{D}$ ratios.) amorphous carbon atoms (not shown here). The Raman mapping images in Fig. 7 show that the CNT fibers displayed a uniform $I_{\mathrm{G}} / I_{\mathrm{D}}$ ratio over a wide area. (The number on the color bar indicates the value of the $I_{\mathrm{G}} / I_{\mathrm{D}}$ ratio.) These results suggested that the CNT fibers did not vary significantly over the observed area.

The strengths of the CNT fibers obtained in our experiments are shown in Fig. S2-1 and Table S1. $\dagger$ The strength of our CNT fibers trends to decrease with the decreasing quality of CNTs (from SWCNTs, DWCNTs to MWCNTs). This trend is in accordance with the results of Raman analysis appeared in Fig. 7. The $I_{\mathrm{G}} / I_{\mathrm{D}}$ ratio also decreases with the quality of CNTs.

The direct spinning methods considered in this work (using methane, ferrocene, and sulfur) are advantageous over other fabrication methods for producing high-quality CNT fibers. The CNT synthesis was carried out at higher temperatures (exceeding $1100^{\circ} \mathrm{C}$ ) than the temperature used for forest spinning $\left(700-800{ }^{\circ} \mathrm{C}\right)$. It is this high temperature that allowed for the rapid synthesis of high-quality CNTs. The residence time in the reaction zone was, therefore, extremely short ( 4.2 seconds in our case) compared with the synthesis time (minutes) ${ }^{42,43}$ of the Si wafer-based CNT fiber synthesis or the synthesis time (hours) ${ }^{44,45}$ of the vapor-grown carbon fibers (VGCFs). Moreover, the synthesized CNTs quickly passed through the reaction zone, so the adsorption of amorphous carbon atoms on the surfaces of the synthesized CNTs was greatly reduced. In our experiments, the Reynolds number was about 150 (laminar flow region) and the fluid flow inside the vertical reactor remained very stable. The effects of back flow were negligible. The use of sulfur was important for keeping the catalyst size small, resulting in thin-walled, high-quality CNTs.

\section{Conclusions}

Here, we investigated the effects of sulfur on catalyst formation and CNT synthesis during the direct spinning of CNT fibers. We obtained direct experimental evidence that sulfur atoms on the catalyst surface suppressed the aggregation of iron catalyst particles, resulting in smaller catalyst particles and thin-walled, high-quality CNTs. We fabricated SWCNT fibers with a high $I_{\mathrm{G}} /$ $I_{\mathrm{D}}$ ratio of 26.9 using methane, ferrocene, and sulfur as the gaseous feeds, indicating that the CNT fibers were mainly composed of SWCNTs having a very high quality. These results suggested that the time period during which sulfur atoms contacted the iron catalyst particles offered a practical handle for controlling the morphology and quality of the synthesized CNTs during the fabrication of CNT fibers. As a demonstration, we devised a simple modification of the experimental setup in which the length of the sulfur injection tube was varied. This minute modification enabled control over the type of CNTs synthesized: mostly SWCNTs, mostly DWCNTs, or mostly MWCNTs, during the direct spinning of CNT fibers. The $I_{\mathrm{G}} / I_{\mathrm{D}}$ ratio was accordingly controlled from 26.9 to 1.5 , indicating the quality of the synthesized CNTs. The understandings obtained from this work provide useful guides for scaling up the direct spinning of CNT fibers. 


\section{Acknowledgements}

The present study was supported by a Korea Science and Engineering Foundation (KOSEF) grant funded by the Korean government (MEST) (Grant no. 2014-003266). We also acknowledge the Research Institute of Industrial Science \& Technology for financial support.

\section{Notes and references}

1 R. H. Baughman, A. A. Zakhidov and W. A. de Heer, Science, 2002, 297, 787-792.

2 M. Endo, M. S. Strano and P. M. Ajayan, Top. Appl. Phys., 2008, 111, 13-62.

3 M. F. De Volder, S. H. Tawfick, R. H. Baughman and A. J. Hart, Science, 2013, 339, 535-539.

4 W. I. Milne, K. B. K. Teo, G. A. J. Amaratunga, P. Legagneux, L. Gangloff, J. P. Schnell, V. Semet, V. T. Binh and O. Groening, J. Mater. Chem., 2004, 14, 933.

5 N. de Jonge, Y. Lamy, K. Schoots and T. H. Oosterkamp, Nature, 2002, 420, 393-395.

6 C. Emmenegger, P. Mauron, P. Sudan, P. Wenger, V. Hermann, R. Gallay and A. Züttel, J. Power Sources, 2003, 124, 321-329.

7 M. Endoa, Y. A. Kim, T. Hayashi, K. Nishimura, T. Matusita, K. Miyashita and M. S. Dresselhaus, Carbon, 2001, 39, 12871297.

8 K. Jiang, Q. Li and S. Fan, Nature, 2002, 419, 801.

9 H. W. Zhu, C. L. Xu, D. H. Wu, B. Q. Wei, R. Vajtai and P. M. Ajayan, Science, 2002, 296, 884-886.

10 Y. L. Li, I. A. Kinloch and A. H. Windle, Science, 2004, 304, 276-278.

11 B. Vigolo, A. Pénicaud, C. Coulon, C. Sauder, R. Pailler, C. Journet, P. Bernier and P. Poulin, Science, 2000, 290, 1331-1334.

12 K. Koziol, J. Vilatela, A. Moisala, M. Motta, P. Cunniff, M. Sennett and A. Windle, Science, 2007, 318, 1892-1895.

13 R. J. Mora, J. J. Vilatela and A. H. Windle, Compos. Sci. Technol., 2009, 69, 1558-1563.

14 J. Foroughi, G. M. Spinks, G. G. Wallace, J. Oh, M. E. Kozlov, S. Fang, T. Mirfakhrai, J. D. Madden, M. K. Shin, S. J. Kim and R. H. Baughman, Science, 2011, 334, 494-497.

15 A. E. Aliev, J. Oh, M. E. Kozlov, A. A. Kuznetsov, S. Fang, A. F. Fonseca, R. Ovalle, M. D. Lima, M. H. Haque, Y. N. Gartstein, M. Zhang, A. A. Zakhidov and R. H. Baughman, Science, 2009, 323, 1575-1578.

16 A. B. Dalton, S. Collins, E. Muñoz, J. M. Razal, V. H. Ebron, J. P. Ferraris, J. N. Coleman, B. G. Kim and R. H. Baughman, Nature, 2003, 423, 703.

17 E. Muñoz, A. B. Dalton, S. Collins, M. Kozlov, J. Razal, J. N. Coleman, B. G. Kim, V. H. Ebron, M. Selvidge, J. P. Ferraris and R. H. Baughman, Adv. Eng. Mater., 2004, 6, 801-804.

18 M. E. Kozlov, R. C. Capps, W. M. Sampson, V. H. Ebron, J. P. Ferraris and R. H. Baughman, Adv. Mater., 2005, 17, 614-617.
19 L. Viry, C. Mercader, P. Miaudet, C. Zakri, A. Derré, A. Kuhn, M. Maugey and P. Poulin, J. Mater. Chem., 2010, 20, 3487.

20 T. Mirfakhrai, J. Oh, M. E. Kozlov, S. Fang, M. Zhang, R. H. Baughman and J. D. W. Madden, IEEE ASME Trans Mechatron, 2011, 16, 90-97.

21 T. Mirfakhrai, J. Oh, M. Kozlov, E. C. W. Fok, M. Zhang, S. Fang, R. H. Baughman and J. D. W. Madden, Smart Mater. Struct., 2007, 16, S243-S249.

22 T. Mirfakhrai, J. Oh, M. Kozlov, S. Fang, M. Zhang, R. H. Baughman and J. D. W. Madden, J. Electrochem. Soc., 2009, 156, K97.

23 H. Zhao, Y. Zhang, P. D. Bradford, Q. Zhou, Q. Jia, F. G. Yuan and Y. Zhu, Nanotechnology, 2010, 21, 305502.

24 Z. Zhu, W. Song, K. Burugapalli, F. Moussy, Y. L. Li and X. H. Zhong, Nanotechnology, 2010, 21, 165501.

25 J. Park and K.-H. Lee, Korean J. Chem. Eng., 2012, 29, 277-287. 26 X. H. Zhong, Y. L. Li, Y. K. Liu, X. H. Qiao, Y. Feng, J. Liang, J. Jin, L. Zhu, F. Hou and J. Y. Li, Adv. Mater., 2010, 22, 692696.

27 M. S. Motta, A. Moisala, I. A. Kinloch and A. H. Windle, J. Nanosci. Nanotechnol., 2008, 8, 2442-2449.

28 M. Kumar and Y. Ando, J. Nanosci. Nanotechnol., 2010, 10, 3739-3758.

29 Y. C. Choi, Y. M. Shin, Y. H. Lee and B. S. Lee, Appl. Phys. Lett., 2000, 76, 2367-2369.

30 W.-H. Chiang and R. M. Sankaran, Diamond Relat. Mater., 2009, 18, 946-952.

31 M. Saeidi and M. Vaezzadeh, Iran. J. Sci. Technol., 2011, 1, 29.

32 A. G. Nasibulin, P. V. Pikhitsa, H. Jiang and E. I. Kauppinen, Carbon, 2005, 50, 2251-2257.

33 J. Wei, H. Zhu, Y. Jia, Q. Shu, C. Li, K. Wang, B. Wei, Y. Zhu, Z. Wang, J. Luo, W. Liu and D. Wu, Carbon, 2007, 45, 21522158.

34 T. P. McNicholas, L. Ding, D. Yuan and J. Liu, Nano Lett., 2009, 9, 3646-3650.

35 V. Reguero, B. Alemán, B. Mas and J. J. Vilatela, Chem. Mater., 2014, 26, 3550-3557.

36 W. Ren, F. Li, S. Bai and H.-M. Cheng, J. Nanosci. Nanotechnol., 2006, 6, 1339-1345.

37 R. M. Sundaram, K. K. Koziol and A. H. Windle, Adv. Mater., 2011, 23, 5064-5068.

38 Q. Zhang, J.-Q. Huang, M.-Q. Zhao, W.-Z. Qian and F. Wei, Appl. Phys. A: Mater. Sci. Process., 2008, 94, 853-860.

39 D.-Y. Peng and J. Zhao, J. Chem. Thermodyn., 2001, 33, 11211131.

40 P. Serp, A. Madroñero and J. L. Figueiredo, Fuel, 1999, 78, 837-844.

41 A. Moisala, A. G. Nasibulin, D. P. Brown, H. Jiang, L. Khriachtchev and E. I. Kauppinen, Chem. Eng. Sci., 2006, 61, 4393-4402.

42 X. Lepró, M. D. Lima and R. H. Baughman, Carbon, 2010, 48, 3621-3627.

43 K. Liu, Y. Sun, L. Chen, C. Feng, X. Feng, K. Jiang, Y. Zhao and S. Fan, Nano Lett., 2008, 8, 700-705.

44 D. K. Mishra and J.-M. Ting, Diamond Relat. Mater., 2008, 17, 598-601.

45 G. G. Tibbetts, Carbon, 1992, 30, 399-406. 